\title{
Reimagining a curriculum in crisis
}

\author{
Darcy Courtland ${ }^{1}$ (DD
}

Accepted: 29 March 2021 / Published online: 20 May 2021

(C) UNESCO IBE 2021

\begin{abstract}
Questioning what knowledge is of most worth in the early weeks of North America's Covid-19 crisis, this article begins to reimagine the possibilities of curriculum in such unprecedented times. It reflects on the author's experiences as a doctoral student to unveil the capacity of a curriculum that emphasizes compassion, community, and relational accountability. It then draws upon Indigenous, ecological, and postmodern curriculum theories to negotiate what an educational response could look like if curriculum approaches focused on holistically nourishing the learner spirit, connectedness, and creating a sense of wonder. The title refers to the current Covid-19 pandemic that requires an immediate reconception of curriculum as the world rapidly shifts. While also nodding to concerns about internalizing "curriculum" as a mastery of outcomes instead of a consideration of lived educational experiences, this article extends an invitation to imagine the possibilities of a curriculum responsive to the ever-changing complexities of life lived.
\end{abstract}

Keywords Curriculum · Covid-19 $\cdot$ Alberta education · Indigenous · Ecological · Postmodern

On Sunday, March 15, 2020, Alberta's chief medical officer, Dr. Deena Hinshaw, announced that Alberta students would not be returning to classrooms the following day and every day that followed for the foreseeable future, due to the unfolding Covid-19 outbreak (CBC News 2020). Our household went quiet. My partner and I-both teachers and myself a doctoral student-questioned what this might mean for us, our teenagers, and Alberta students. In retrospect, the first week passed in a bit of a blur. I found out that I would be laid off as a guest teacher, losing half my salary, to which we had become accustomed. My husband was given different directives each day as his administration, school district, and the province worked to get on the same page. And our own kids started online

Darcy Courtland

mcourtla@ualberta.ca

1 University of Alberta, Elementary Education, 551 Education Centre South, Edmonton, Alberta T6G 2G5, Canada 
learning, bombarded with independent lessons and projects. The only constant was the chaos we all felt.

We all seemed to be expected to carry on, even as the world we knew ceased. While I worried about students who lacked basic needs at home, my husband was instructed to throw together lesson plans for an online classroom. While I worried about our household income, our kids were attending to deadlines and new expectations. And as I worried about the pressure being put on teachers and parents, many of my teacher friends had to negotiate the pressures of being both. Amidst the flurry, it seemed that everyone was questioning what knowledge was of most worth during a global pandemic.

The meaning of the title for this article, Reimagining a curriculum in crisis, is twofold. First, it refers to the current Covid-19 crisis, which required an immediate re-conception of curriculum, as teaching and learning rapidly shifted to being online. The pursuit of imagining and reimagining, as I have come to learn from my dear mentors, Drs. Janice Huber and Trudy Cardinal, is accompanied by a sense of playful wonder. Imagining possibilities of a curriculum creates space to explore without a prescribed need for answers or overt attentiveness to potential barriers or dominant narratives. The title also refers to my concerns for curriculum which are emphasized by colonial and positivist narratives in classroom curricula. As a diverse learner, I am very awake to an ongoing perpetuation of colonial curricular violence. Embracing an understanding of literacy as life lived (Courtland 2020), I acknowledge each learner's experience will be grounds for rich growth and development, even in the midst of a pandemic. My heightened concern comes from the ways by which many educators have been shaped to understand "curriculum" as a mastery of program outcomes instead of as an invitation to consider lived educational experiences. I worry it could be all too easy to accept and retell deficit narratives relating to the loss of classroom time and the "inevitable" gaps in subject specific content. Though I choose to engage in what might be gained, rather than lost, I have already heard and rebuked such rhetoric in personal conversations and across social media. As an alternative, this article extends an invitation to educators and learners alike to consider possible alternatives and affordances of a curriculum responsive to the poetic and ever-changing complexities of life lived today and, in the days to come.

This article outlines my own raw thoughts, feelings, and lived experiences throughout the first month of the Covid-19 crisis in Alberta. Questioning what knowledge is of most worth in such contexts, I draw on the writings of prominent curricular scholars to explore the possibilities of curriculum in these unprecedented times. Straddling multiple worlds, this article reflects my positionality as an emerging scholar, a doctoral student, a teacher on leave, a wife and friend of many teachers, and a stepparent to two youth in schools. In this article, I reflect on my own experiences as a learner to unveil the ways curriculum has been able to respond thus far, through compassion, community, and relational accountability. I then negotiate my imaginations of a classroom curriculum with the capacity to focus on holistically nourishing the learner spirit, connectedness, and creating a sense of wonder. My journey of reimagining is underpinned by philosophies grounded in ecological, Indigenous, and postmodern curricular perspectives. I conclude with the understanding that our pandemic response could shift the way we embrace curriculum as responsive and holistic.

Before I continue, I must acknowledge the privileges I have in this time of uncertainty. Many social, political, and economical complexities go unaddressed in this article, as I write from my own experience and ability to imagine possibilities. I am currently able to do my schoolwork from home, and our family can make ends meet at the end of the month. This is not the case for many Albertans. I recognize and want to make clear this article's limitations as a result of my own positionality. 


\section{This is not normal}

I have caught myself mentioning my own adjustment to "the new normal". Yet, I believe it is extremely important to remember that nothing about teaching and learning in the midst of a global health crisis is normal. We find ourselves in a wholly different milieu, a different social context, in a time that is undoubtedly recognizable for its uniqueness in the educational sector. So why would we expect education to look the same?

After the first week of chaos, the province determined the curricular focus should be on literacy and numeracy for students in kindergarten to Grade 6, with opportunities for cross-curricular social studies and science instruction for grades 4 through 6 (Government of Alberta 2020). Guidelines were also put into place to ensure students and families were not overworked. This meant elementary (K through 6) students would have, on average, 5 hours of work per week. Teachers were to "determine what content to cover based on remaining curricular outcomes and plan tasks that are reasonable to do from home" (para. 3). Junior high (grades 7 through 9) and senior high (grades 10 through 12) learners were expected to continue their language courses, maths, sciences, and social studies. Junior high students would have, on average, 10 hours of schoolwork per week, and high schoolers 3 hours per subject a week.

I was admittedly quite impressed with these guidelines laid out by the province. Autonomy was offered to teachers, and the time periods showed consideration of students and families - suggesting that just maybe prescribed positivist curricular outcomes were not the epitome in the midst of a pandemic. What interested me was the apparent urgency brewing with each news update. A narrative of uncertainty, community, and being present was louder than the previous "back to basics" curriculum push of Alberta's United Conservative Party (UCP).

I am reminded now of curriculum scholar Jackie Seidel's (2014) consideration of mortality and education. Seidel has made the case that education tends to look toward uncertain futures, those of students and society, rather than cultivating awareness and wonder for today. She has noted this contributes to a lack of relationality and intimacy. I wonder if the urgency and mortality accompanying Covid-19 are capable of creating spaces for educators, families, and learners to be more connected in the moment. Maybe education could be hungrier for "compassion, love, life, how we live now" (p. 148)?

\section{Compassion and community}

Given the ambiguity of the times, I believe strongly in the notion of showing compassion to educators, learners, and families. My own experiences of learning in a pandemic emphasized and embodied this grace. Honouring the uncertainty and quickly evolving directives, my professors at the University of Alberta offered my colleagues and me time to adjust to the chaos. I appreciated that, unlike my husband's experience, we were given clear direction from the University about adjusted policies, procedures, and expectations. The University seemed to understand that the onset of the pandemic had been a whirlwind for many, and nothing short of a nightmare for others.

My fellow classmates and faculty mentors were supportive and uplifting as we traversed the uncharted waters together. Postmodern curriculum scholar Patrick Slattery (2012) has offered a way of conceptualizing education as chaotic, nonlinear, and relational. Slattery has emphasized that our "human and natural systems act as strongly coupled, integrated 
systems" (Montenegro and Glavin 2011; Slattery 2012, p. 208), suggesting that in crisis, cultivating cooperative communities will contribute to healing and compassionate classrooms. This approach to curriculum begins to blur the boundaries between life within and beyond the classroom-a concept all too fitting in these current contexts.

I have great appreciation for everyone who shifted their thinking and their practice to ensure classes continued to take place with the same integrity and rigor we have come to expect from a doctoral program, while still being compassionate to the needs and limitations of learners. The fact that the feeling of community, in the courses I was part of, was able to transcend the walls of the physical classroom is a testament to the relational ethics emphasized within course curricula. What has been powerful is that, despite changing to a credit/no-credit model of assessment, each community member continued to contribute to the best of their ability, given individual circumstances.

\section{Accountability}

With my program's switch to students receiving a passing grade, there was less external pressure to attain specific grades. The result for me was eye opening. Having attention deficit hyperactivity disorder (ADHD), I already struggle to be productive by linear, structured standards in times that do not involve global health pandemics, increased screen time, and secluded quarantine. The additional stress and stimulus made it significantly more difficult for me to perform. For me, the University's shift in assessment offered more equitable standards, despite the frustration of many (Fung 2020). Four years of severe academic performance anxiety was met with the warm embrace of stability in a time it was most needed. Though my own academic standing was still incredibly important to me, the chaos, anxiety, and uncertainty I felt while completing courses during the Covid-19 pandemic would have been crippling if I had to worry about grades. With the additional stress of the pandemic being honoured and met with such grace, the intensity of my emotions was alleviated, enabling me to approach my daily life and my studies with a clearer mind and spirit. Yet, not once did I feel I was not accountable for my own participation and progress.

An unfortunate priority in education seems to be that teachers and students are held accountable for productivity through a colonial lens of how things are supposed to be done (Seidel 2014; Steel 2012). I have recently seen this manifest as micromanagement from teachers requiring students to check in daily at prescribed times to administrators asking for daily reports from teachers working at home that outline an hour-by-hour workday. The desire to ensure everyone is fulfilling their roles and responsibilities is indeed of importance, but I wonder what it might look like if we shifted toward fostering relational accountability amongst teachers and learners?

The reality of teaching and learning is a subjective experience, multilayered and complex (Aoki 2005; Riley-Taylor 2009; Slattery 2012), a concept often emphasized in postmodern curriculum theories. This understanding locates the learner/educator at the center of their own experience; however, we recognize they are not learning or teaching in isolation. Elaine Riley-Taylor (2010), an ecological curriculum philosopher has referred to this as the relational self, "an expansion of human knowing, ... always in relation to a given context" (p. 289). Curricular scholar Sean Steel (2012) has posited, "Our own educational biases, modelled as they are on 'accountability' in learning and assessment, do not recognize let alone cultivate [the soul's pursuit of wisdom] even though such activities constitute the 'highest happiness' for human beings" (p. 55). In honouring both individually and community, many Indigenous and wisdom tradition curricular scholars draw on relational 
ethics as integral to learning communities (Kirkness and Barnhardt 1991; Riley-Taylor 2009; Smith 2006; Tanaka 2016; Wilson 2008).

Relational accountability is enacted through respect, relevance, reciprocity, and responsibility (Kirkness and Barnhardt 1991). Michele Tanaka (2016), an indigenist, cross-cultural curriculum scholar, has emphasized that relational accountability is nurtured first through the creation of community, allowing time for members of learning communities to walk alongside one another. She has noted this pursuit is encompassed by a need to dismantle Eurocentric understandings of hierarchical power dynamics, allowing for more personal connections to teaching, learning, and understanding. Opaskwayak Cree scholar Shawn Wilson (2008) has offered that we exist only in relationship, and thus are always accountable to others. Similarly, David Geoffrey Smith (2006) has said,

The world can be imagined as a cast of people of different traditions and experience, all of whom possess civilizational practises of one kind or another, characterizable by greater or lesser degrees of success or failure, and who always participate within a global community in which every member can be held to a certain ethical accountability in relation to every other member. (p. 45)

It is evident our actions and inactions affect not only ourselves but a network of others. This continues to ring true in these times.

I believe that teachers will continue to uphold their professionalism and quality of teaching to the best of their ability, because of the relational accountability that has been established within their learning environments. In many cases, I also believe this to be true of students. Just the other day, my husband remarked how students who previously struggled to hand in class work had begun to be more vocal and enthusiastic about completing assignments. Although there are a myriad of reasons for this I am sure, I cannot help but wonder if, as was observed in Tanaka's (2016) research, the shift in classroom power dynamics has cultivated a heightened sense of purpose for some learners.

Having outlined my own experiences of compassion, community, and relational accountability, I feel more confident in the many ways educational systems could be negotiating rapid changes in the light of this pandemic. Nevertheless, I continue to fear that online education, used as an emergency response, has the potential to isolate learners, thus neglecting their learning spirits (Battiste 2010). In the following sections, I aim to imagine the possibilities for a curriculum that attends holistically to learners, connecting us despite the isolation many might be feeling.

\section{Curriculum of nourishment and sustainability}

It was northern Alberta scholar Brent Davis (2018) who first provoked me to begin thinking with curriculum as an ecosystem: "An expanded awareness of humanity's entanglements with other lifeforms" (p. 197). Similarly, Riley-Taylor (2010) has positioned herself alongside this relational metaphor, with the emphasis that "human lives are lived in process ... within relational cycles" (p. 294). She has gone on to describe that this conceptualization of an "ecology of living" (p. 295) is multilayered, requiring individuals to pursue self-awareness and recognize their self in relationship to place. I am called to reflect on Riley-Taylor's detailed narrative of a diverse ecosystem in balance, making the connection between the sustained harmony she has described and today's classroom.

Riley-Taylor (2010) has made the critical point that, through recognizing the relationality of all living things, we must also acknowledge the need for contextual and local 
curriculum. By viewing curriculum solutions through Pinar's articulation of "careful, thoughtful, disciplined understanding" (p. 288), Riley-Taylor has articulated curriculum as opened up to "more embodied forms of knowledge ... according to what makes sense within [curriculum scholars'] given context[s] and based upon their personal ways of knowing" (p. 288). This way of viewing curriculum interrupts a colonial framework by including not only mental/rational ways of knowing but also "incorporating the knowing of the body, the heart, and even the spirit" (p. 289).

Within an Indigenous paradigm is an understanding that all of us are four-part people: body; mind; heart; and spirit. Indigenous education seeks to nourish all four parts of us. Mi'kmaq scholar Marie Battiste (2010) has understood learners to have a learning spirit. Her belief is that Eurocentric ways of teaching and learning have neglected or even wounded this spirit, and thus curriculum and instruction must nourish it. Herbert John Benally (1993), a Navajo scholar, has suggested,

When we are not taught in this way, drawing on all four areas of knowledge, we become spiritually, emotionally, socially, physically and environmentally impoverished. We become narrow in our views and cannot see the connection between all knowledge. We wind up perpetuating the imbalance within and between ourselves, other people and the natural world. (as cited in Battiste 2010, p. 16)

Educators today may ask themselves in what ways Western educational practices have crushed or wounded learning spirits previously. Are those ways being re-inflicted or resolved in online learning environments?

Paulo Freire (1985) posited that the pedagogy of teachers can never be neutral: "Education must be either liberating or domesticating" (p. 17). As such, inquiring into one's positionality as an educator is both vital and timely. Acknowledging one's understandings of curriculum, and the influences that have shaped them, is a commitment to ensure their contributions to teaching and learning are not among the domesticating voices within dominant narratives. Yet, merely examining hegemonic values embedded in research and practice is not enough on its own to disrupt colonial narratives so deeply imbedded historically within Eurocentric scholarship. Freire offered, "The only way to ... unveil reality, is to create a counter-ideology to help us break the dominant ideology" (p. 18). It is this imbalance Benally (1993) has spoken of - the one I have come to know in only a month-that urges me to think more deeply with how curriculum might holistically nourish learners in hopes of creating a counter ideology.

When it comes to getting to know and connecting with oneself as a four-part learner, reflexivity was mentioned in Tanaka's (2016) research as a significant process, based on the understanding that you have to return inward before you can move forward. Riley-Taylor (2010) has echoed these sentiments through her own understanding of an embodied curriculum. Both Riley-Taylor and Tanaka have drawn on the layers and complexities of self within various social, cultural, and environmental milieus, illustrating that inviting learners to connect to all four parts requires an intentional slowing down and creating space. Both scholars, along with Slattery (2012), have suggested a need to be grounded, rooted in a sense of self and place, and aware of the interconnectedness that is all encompassing.

It is Davis (2018) who continues to call me to remember that education is, or at least should be, sustenance. Acknowledging that I have neglected many parts of my four-part person as of late, I wonder, if in the midst of chaos, teaching and learning can be sustaining. I imagine an open-ended curriculum that provides opportunities for learners to connect mentally, emotionally, physically, and spiritually. A curriculum of nourishment and sustenance honours and roots itself in learners' connection to self 
(as a four-part person); to others; to the world around them; and possibly to a higher power, depending on personal beliefs.

\section{Curriculum of interconnection and connectedness}

Indigenous, ecological, and postmodern curriculum theories all "[celebrate] the interconnectedness of knowledge, learning experiences, ... communities, the natural world, and life itself (Slattery 2012, p. 218). Due to current socializing restrictions, most teachers and learners find themselves less physically connected to the outside world, and instead are much more connected with people and places within their homes. This is an important place for curriculum to start. I admit, as a teacher, I have found myself noting how a busier world and abundant technologies seem to have contributed to less family socialization. Youth seem to be coming to school with less socialization, sense of self, and connection to the outdoors (Tanaka 2016). Amidst this crisis, many students are afforded more time to disconnect from the external pressures of school and extracurriculars, while also having more time to connect. Research has supported a reciprocity in connection that feeds teaching and learning (Seidel 2014; Slattery 2012; Tanaka 2016).

As I write this, I am aware of my husband upstairs and his video chat with students before they all part for spring break. I can hear so much joy from the call and I am reminded of my own pandemic-impacted learning journey and the positive connections that continue to form with each passing week. In this context, my university colleagues and I are connected not only by our relationships, but through our shared experiences. John Dewey (1938) argued that students must have various experiences and connections in order to enrich their learning, I would imagine this to be especially true while in physical isolation. Also holistic in nature, these educative experiences need to be open ended to fit each learner within their context, yet openended does not mean offered without great thought. Educational experiences that connect learners with themselves, others, and the world around them often require educators to plan thoughtfully and to connect with their learners (Seidel 2014; Slattery 2012; Tanaka 2016).

Seidel (2014) has elaborated on how being in relationship with the earth and one another will lead to a deep appreciation of being but one woven thread in a grander ecosystem-connected but not central. This is an extremely powerful thought for youth and adults to think with in relation to the Covid-19 pandemic. When first reading her work toward the beginning of 2020, I was jarred by Seidel's description of humans as helpless beings in the finite nature of the world. Little did I know that merely a month later, this concept would be hitting closer to home than I could have imagined. Nodding to discomfort, Seidel has invited educators to summon the courage to dispel egocentric conceptions of curriculum and instead embrace and honour the reciprocity of relationships within and beyond the classroom. The holistic nature of this way of teaching reconnects youth to all their relations and supports ecological reciprocity, as described by Tanaka (2016), ultimately supporting a more sustainable future. 


\section{Curriculum of wonder}

In a time of complexity and crisis, I must ask how we might create spaces for wonder in classrooms? The way I see it, three concepts support a curriculum of wonder: time, hospitality, and playfulness. Considering the implementation of new provincial directives, I believe we can agree there is time to slow down and engage in wonder. Secondly, my understanding of hospitality comes from Jen Gilbert (2006), who has described the law of hospitality as an unconditional welcome. She has posited that a teacher's sense of knowing and understanding has no precedence when inviting queerness, rather, we must genuinely welcome who and what turns up. The same can be said about extending an open invitation for wonder. I believe this unconditional welcoming that waits not for comfort is integral to being a teacher, researcher, and curriculum scholar.

Steel (2012) has cautioned that education all too often "encourages students to beware of demonstrating what they do not know" (p. 48), rather than delight in discovery. I believe this stands true for educators as well and is closely tied to teachers' discomforts with uncertainty. Nevertheless, "[education] suggests that we teachers should be constantly asking questions of ourselves and of our students, to create a spirit in which we are certain by not being certain of our certainties" (Freire 1985, p. 17). Furthermore, Riley-Taylor (2010), has reminded us:

An ecology of living would acknowledge that there are times when all cannot be controlled and when that which can be known is only that uncertainty exists; that there are times when truth must be recognized in terms of its plurality, provisional truths that are relative to one context, the scale of a particular circumstance, time, or place. (p. 295)

Without room for students to wonder, where is there room for agency, creativity, and criticality?

Lastly, the word playful comes to mind as I think about how we are naturally curious beings. It is my hope that teachers see and take up the revised governmental directives as open ended to enable the playfulness and wonder that teaching and learning can offer. Without being completely bound by prescriptive outcomes, might there be even more wonder present in curriculum? I personally see it as integral to creating space for wonder within a curriculum for richer educational opportunities today, leading to better problem solving tomorrow.

\section{Current conclusions}

As the fourth week of Alberta's physical distancing comes to an end, our district is pausing for spring break and the University's winter term is wrapping up. I am thankful for this gift of slowing down and being present. For our family, and I hope for many others, this will be a time of reconnecting to self, to each other, and to calm. I already wonder if these notions of reconnection will support the ways we approach teaching and learning in a week's time.

My own positionality as a doctoral student and educator has supported me in thinking alongside teachers and learners in a time of global health crisis. Through this article, I have attempted to uncover how we might approach curriculum in a way that honours teachers, students, families, and the chaos and complexity of current times. I have touched 
on the significance of community, connectedness, and nourishing and sustaining the learning spirit as I imagine the possibilities for a curriculum in crisis. What I have yet to touch upon are the global and historical aspects of such a time. This pandemic is happening on a global scale and is huge in terms of living history. It is having an impact on our future. The question in my mind now is "How will these lived experiences contribute to imagining curriculum in a post-crisis era?" Only time will tell.

\section{References}

Aoki, T. (2005). Layered voices of teaching: The uncannily correct and the elusively true. In W. G. Pinar \& R. L. Irwin (Eds.), Curriculum in a new key: The collected works of Ted T Aoki (pp. 187-197). Mahwah, NJ: Lawrence Erlbaum.

Battiste, M. (2010). Nourishing the learning spirit: Living our way to new thinking. Canadian Educational Association, 50(1), 14-18.

Benally, H. J. (1993). Navajo traditional knowledge and implications. In Flake, C. L. (Ed.), Principles, perspectives and practices. A book of readings based on Education 2000: A holistic perspective (p. 5). Brandon, VT: Holistic Education Press.

CBC News (2020, March 15). Alberta cancels K-12 classes, closes child-care centres due to COVID-19 pandemic. CBC News Edmonton. https://www.cbc.ca/news/canada/edmonton/covid-coronavirusupdate-hinshaw-alberta-edmonton-1.5498467

Courtland, D. (2020). Becoming a (re)searcher: Negotiating literacies and uncertainty. Language and Literacy Journal, 22(1), 24-38.

Davis, B. (2018). On the many metaphors of learning....and their associated educational frames. Journal of Curriculum Studies, 50(2), 182-203.

Dewey, J. (1938). Experience and education. New York, NY: Macmillan.

Freire, P. (1985). Reading the world and reading the word: An interview with Paulo Freire. Language Arts, 62(1), 15-21.

Fung, N. (2020, April 1). Universities differ on whether a pass-fail grading scheme should be optional. University Affairs. https://www.universityaffairs.ca/news/news-article/universities-differ-on-whether-apass-fail-grading-scheme-should-be-optional/

Gilbert, J. (2006). "Let's say yes to who or what turns up": Education as hospitality. Journal of the Canadian Association for Curriculum Studies, 4(1), 25-34.

Government of Alberta (2020). Covid-19: Education and child care. https://www.alberta.ca/student-learn ing-during-covid-19.aspx

Kirkness, V., \& Barnhardt, R. (1991). First nations and higher education: The fours Rs—respect, relevance, reciprocity, responsibility. Journal of American Indian Education, 30(3), 1-15.

Montenegro, M., \& Glavin, T. (2011). Scientists offer new insights into what to protect in the world's rapidly vanishing languages, cultures, and species. SeedMagazine.

Riley-Taylor, E. (2010). Reconceiving ecology: Diversity, language, and horizons of the possible. In E. Malewski (Ed.), Curriculum studies handbook: The next moment (pp. 286-297). New York, NY: Routledge..

Seidel, J. (2014). Losing wonder: Thoughts on nature, mortality, education. In J. Seidel \& D. W. Jardine (Eds.), Ecological pedagogy, Buddhist pedagogy, hermeneutic pedagogy (pp. 132-152). New York, NY: Peter Lang.

Slattery, P. (2012). Curriculum development in the postmodern era (3rd ed.). New York, NY: Routledge.

Smith, D. G. (2006). Trying to teach in a season of great untruth: Globalization, empire and the crises of pedagogy. Rotterdam: Sense.

Steel, S. (2012). Recovering ancient and medieval contemplative taxonomies as an alternative to Bloom's taxonomy of educational objectives. Paideusis, 20(2), 46-56.

Tanaka, M. (2016). Learning and teaching together: Weaving Indigenous ways of knowing into education. Victoria, British Columbia: UBC Press.

Wilson, S. (2008). Research is ceremony. Halifax, NS: Fernwood.

Publisher's Note Springer Nature remains neutral with regard to jurisdictional claims in published maps and institutional affiliations. 
Darcy Courtland is a third-year doctoral student in the Department of Elementary Education at the University of Alberta. She is of Irish-settler heritage and carries family stories of being a fifth- and thirteenthgeneration guest on Turtle Island. She is of the shores of Lake Superior, the foothills of the Rocky Mountains, and of Montreal maples. She currently holds a full-time professional position as a learning leader and diverse learner advocate within her K-6 school in Mohkinstsis/Calgary, traditional Treaty 7 territory. Darcy's passion for language and literacies, social studies education, and personalized learning has been brought to life in the elementary classroom for more than 9 years. Darcy's current research interests are in the areas of vulnerability and story in research as well as education for reconciliation. Her proposed doctoral research seeks to better understand the personal and professional learning journeys of non-Indigenous teachers as they make personal commitments to reconciliation. 